\title{
Isolation and Culture of Fibroblasts, Vascular Smooth Muscle, and Endothelial Cells From the Fetal Rat Ductus Arteriosus
}

\author{
SVEN C. WEBER, ALEXANDER GRATOPP, SANDRA AKANBI, CORNELIA RHEINLAENDER, HANNES SALLMON, \\ PAYMAN BARIKBIN, AND PETRA S. KOEHNE
}

\author{
Departments of Neonatology [S.C.W., S.A., C.R., H.S., P.B., P.S.K.]; General Pediatrics [A.G.], Charité-University Medicine Berlin, \\ Campus Virchow Hospital, 13353 Berlin, Germany
}

\begin{abstract}
The ductus arteriosus (DA), a fetal arterial shunt vessel between the proximal descending aorta and the pulmonary artery, closes shortly after birth. Initial functional closure as a result of the DA's smooth muscle contraction is followed by definite anatomical closure. The latter involves several complex mechanisms like endothelial cushion formation and smooth muscle cell migration resulting in fibrosis and sealing of the vessel. These complex steps indicate highly specialized functions of the DA vascular smooth muscle cells (VSMCs), endothelial cells, and fibroblasts. Herein, we describe a new reproducible method for isolating VSMCs, endothelial cells, and fibroblasts of high viability from fetal rat DA using immunomagnetic cell sorting. Purity of the different cell cultures was assessed by immunohistochemistry and flow cytometry and ranged between 85 and 94\%. The capability of the VSMCs to react to hypoxic stimuli was assessed by intracellular calcium and ATP measurements and by VEGF mRNA expression analysis. VSMCs respond to hypoxia with decreases in intracellular calcium concentrations and ATP levels, whereas VEGF mRNA expression increased 3.2-fold. The purified vessel-specific different cell types are suitable for subsequent gene expression profiling and functional studies and provide important tools for improving our understanding of the complex processes involved in the closure of the DA. (Pediatr Res 70: 236-241, 2011)
\end{abstract}

$\mathrm{T}$ he ductus arteriosus (DA) is a shunt which connects the proximal descending aorta and the main pulmonary artery (PA). During fetal life, it serves to bypass the pulmonary circulation. The DA closes shortly after birth, and pulmonary blood flow increases during late gestation (1). After birth, an abrupt increase in oxygen tension results in ductal constriction, which is further promoted by falling levels of prostaglandin E2 because of an increased pulmonary metabolism and the elimination of placental prostaglandin. DA medial smooth muscle contraction leads to wall thickening, luminal obliteration, and shortening of the vessel. Permanent sealing of the DA is a process generated by the infolding of the endothelium, neointima formation, subintimal disruption, and vasa vasorum ingrowth resulting in subsequent vessel fibrosis. Several major molecular pathways are known to be involved in this programmed proliferation during permanent closure of the DA, e.g. NO signaling, the system of VEGF-promoted angiogenesis, and the cyclooxygenase/prostaglandin system (2-5).

Received September 13, 2010; accepted March 10, 2011.

Correspondence: Petra Koehne, M.D., Department of Neonatology, Charité, Campus Virchow-Klinikum, Augustenburger Platz 1, D-13353 Berlin, Germany; e-mail: petra.koehne@charite.de

Supported by a Rahel-Hirsch research grant.
However, many questions concerning the exact function and cross-talk of these signaling pathways and the molecular basis for failed DA closure still remain unanswered (6). Previous studies investigating molecular events in the duct were in part hampered by the lack of an in vitro model that allows to study the processes in question separately in each of the different cell types of the DA instead of using the whole vessel (7). Herein, we describe an improved and reproducible method to culture organotypic vascular smooth muscle cells (VSMCs), fibroblasts, and endothelial cells (ECs) of high purity and viability from the fetal DA that may serve subsequent functional and molecular studies.

\section{METHODS}

Animal preparation. Experiments were performed according to the institutional guidelines and national animal protection laws and have been approved by the Charité-Universitätsmedizin Berlin Animal Care and Use Committee (project number T0259/04). Wistar rats, timed-pregnant $21 \mathrm{~d}$ (E 1 = plug date) were killed by $\mathrm{CO}_{2}$ anesthesia and cervical dislocation. After opening the uterus, the fetuses were removed and kept on ice in PBS at $\mathrm{pH}$ 7.4. Pups were killed by decapitation, and the thoracic cavity was opened by a midline incision. The following micropreparation steps were performed under a dissection microscope (Leica M690, lens 10445170, 10X21B; Leica Mikrosysteme Vertriebs GmbH, Bensheim, Germany). The pericardium was opened and the situs with the DA and the great vessels was rinsed with PBS $\left(\mathrm{pH} 7.4,4^{\circ} \mathrm{C}\right)$. The DA was dissected and trimmed at its aortic origin and at the level where the two PAs branch out and placed in VSMC medium (DMEM, $3.7 \mathrm{~g} / \mathrm{L} \mathrm{NaHCO}$, $15 \%$ FCS, $1 \%$ penicillin/streptomycin, $1 \%$ L-glutamine, No. F0405; Biochrom AG, Berlin, Germany).

EC culture. The tissues were transferred to a $1.5-\mathrm{mL}$ centrifuge tube containing $1 \mathrm{~mL}$ of collagenase $1 \mathrm{mg} / \mathrm{mL}$ (collagenase:aqua dest.-1:4; Biochrom AG) and incubated at $37^{\circ} \mathrm{C}$ for $7 \mathrm{~min}$. Digestion was stopped by adding $2 \mathrm{~mL}$ of EC medium (Medium 199 EARLE, $2.2 \mathrm{~g} / \mathrm{L} \mathrm{NaHCO} 3,20 \%$ FCS, $1 \%$ penicillin/streptomycin, 1\% L-glutamine, No. F0615; Biochrom AG). Then the cell suspension was centrifuged for $5 \mathrm{~min}\left(1000 \mathrm{rpm}, 4^{\circ} \mathrm{C}\right)$ and the pellet resuspended in EC medium. Next, the cell suspension was filtered through a $40-\mu \mathrm{m}$ metal mesh once, and cells were disseminated into $250-\mathrm{mL}$ $\left(75 \mathrm{~cm}^{2}\right.$ ) gelatin-coated cell culture flasks (Falcon, Becton Dickinson, Heidelberg, Germany) in EC medium containing 1\% fibroblast growth factor 1.

Fibroblast/VSMC culture. To isolate VSMCs and fibroblasts, the prepared tissues were dissociated enzymatically at $37^{\circ} \mathrm{C}$ overnight in an incubation solution of $1 \mathrm{~mL}$ VSMC medium containing the following: collagenase type II $1 \mathrm{mg} / \mathrm{mL}$ (Biochrom AG), elastase $0.2 \mathrm{mg} / \mathrm{mL}$ (Roche, Basel, Switzerland), trypsin inhibitor $0.5 \mathrm{mg} / \mathrm{mL}$, BSA $2.0 \mathrm{mg} / \mathrm{mL}$, and DNAase type I $0.1 \mathrm{mg} / \mathrm{mL}$ (Sigma Chemical Co.-Aldrich, Hamburg, Germany) (8). The digestion was stopped by adding $2 \mathrm{~mL}$ of VSMC medium. Then the cell suspension was centrifuged for $5 \mathrm{~min}\left(1000 \mathrm{rpm}, 4^{\circ} \mathrm{C}\right)$, and the pellet was resuspended in

Abbreviations: EC, endothelial cell; FCM, flow cytometry; MACS, magnetic-activated cell sorting; MTT, 3-(4,5-dimethylthiazol-2-yl)-2,5-diphenyltetrazolium bromide; PA, pulmonary artery; VSMC, vascular smooth muscle cell; vWF, von Willebrand factor 
VSMC medium. Finally, the cell suspension was filtered through a $40-\mu \mathrm{m}$ metal mesh once, and cells were disseminated into $250-\mathrm{mL}$ cell culture flasks.

Magnetic-activated cell sorting (MACS). All the cells isolated from the fetal DA were subjected to magnetic labeling and separation. Separation of target cells can be achieved by applying positive or negative selection. Positive selection is a direct and specific way to isolate the target cells from a heterogeneous cell suspension. Negative selection allows the isolation of the cell population of interest by removing all other cell types from the sample. Here, these two different separation strategies were combined in a sequential sorting of cell subsets where ECs and fibroblasts were isolated by means of positive selection and VSMCs by means of negative selection.

EC purification. Confluent adherent ECs were rinsed with PBS (pH 7.4, $\left.20^{\circ} \mathrm{C}\right)$ once and incubated with $1 \mathrm{~mL}$ accutase $\left(5 \mathrm{~min}, 37^{\circ} \mathrm{C}\right)$. The digestion was stopped by adding $2 \mathrm{~mL}$ VSMC medium. The cells were detached using a rubber policeman and resuspended in VSMC medium. Then the cells were isolated by passing them through a 22-gauge needle for 10 to 15 times and cell concentration was determined. After an additional washing step (PBS, $\mathrm{pH} 7.4$, $\left.20^{\circ} \mathrm{C}\right)$, cells were resuspended in $1 \mathrm{~mL}$ RPMI medium $\left(20^{\circ} \mathrm{C}, 5.5 \mathrm{~g} / \mathrm{L} \mathrm{NaCl}\right.$, $5 \mathrm{mg} / \mathrm{L}$ phenol red, $2.0 \mathrm{~g} / \mathrm{L} \mathrm{NaHCO}_{3}, 25 \mathrm{mM}$ HEPES, $0.532 \mathrm{~g} / \mathrm{L}$ L-glutamine, No. 0972 G; Biochrom AG) and filtered through a 40- $\mu$ m metal mesh. The cells were incubated with the primary antibody [5 $\mu \mathrm{g} / 200,000$ cells, IgG rabbit anti-rat von Willebrand factor (vWF) polyclonal, No. ab 6994; Abcam, Cambridge, England] at $20^{\circ} \mathrm{C}$ for $30 \mathrm{~min}$. After washing and resuspension in $80 \mu \mathrm{L}$ MACS buffer (PBS, 5\% BSA, and $2 \mathrm{mM}$ EDTA), cells were incubated with magnetic beads $(20 \mu \mathrm{L}$, goat anti-rabbit IgG, No. 486-02; Miltenyi Biotec, Auburn, CA), following the manufacturer's instructions. Magnetically labeled $\mathrm{vWF}+$ cells were isolated using a magnetic column (LS MACS separation columns; Miltenyi Biotec). The vWF+ eluate was resuspended in EC medium and cultured in $250-\mathrm{mL}$ cell culture flasks.

Fibroblast purification. Confluent adherent mixed cell cultures mainly consisting of VSMCs and fibroblasts were detached, isolated, and filtered analog to the ECs. The remaining effluent after positive selection of ECs was collected and kept for the separation of VSMCs and fibroblasts. Fibroblast purification was performed by using a specific primary antibody $(2.5 \mu \mathrm{g} / 1 \times$ $10^{6}$ cells, biotinylated mouse anti-rat CD90, Thy-1, isotype $\operatorname{IgG} 2 \alpha$, MAb, No 554893; BD Biosciences, Erembodegem, Belgium) at $20^{\circ} \mathrm{C}$ for $30 \mathrm{~min}$. After washing and resuspension in $80 \mu \mathrm{L}$ MACS buffer, cells were incubated with magnetic beads $(20 \mu \mathrm{L}$, streptavidin-coupled goat anti-mouse IgG, No 130-048-101; Miltenyi Biotec), following the manufacturer's instructions. Magnetically labeled CD90+ cells were isolated using a magnetic column (LS MACS separation columns; Miltenyi Biotec). The CD90+ eluate was resuspended in VSMC medium and cultured in $250-\mathrm{mL}$ cell culture flasks.

VSMC purification. VSMCs were isolated by removing all other cell types from the sample. Accordingly, the remaining effluent after isolating ECs and fibroblasts was resuspended in $5 \mathrm{~mL}$ RPMI medium. After washing, the cells were resuspended in VSMC medium and disseminated into $250-\mathrm{mL}$ cell culture flasks. VSMC cell cultures underwent up to three passages and were cultured for $15 \mathrm{~d}$ for all functional studies (measurements of free cytoplasmatic calcium, ATP levels, and VEGF mRNA quantification).

Flow cytometry analysis. Experiments were performed using a FACScanTM flow cytometer (Becton Dickinson), equipped with a 488-nm argon laser, which detects surface or intracellular antigen expression on separated cells by means of MAb labeled with different fluorescent probes. Briefly, cells were incubated with antibodies directed at anti-rat CD $90(2 \mu \mathrm{g} / 50,000$ cells, mouse IgG $2 \alpha$, No. 554893; BD Biosciences), anti-rat vWF $(15 \mu \mathrm{g} / 50,000$ cells, rabbit IgG, No. ab 6994; Abcam), and anti-rat actin ( $1 \mu \mathrm{g} / 50,000$ cells, mouse IgG $2 \alpha$, No. 06520; Dianova, Hamburg, Germany) at $4^{\circ} \mathrm{C}$ for $30 \mathrm{~min}$, washed twice, and then incubated with a secondary fluorescence-labeled antibody [7.5 $\mu \mathrm{g} / 50,000$ cells, goat anti-rabbit IgG-FITC (fluoresceinisothiocyanate), No. FI-1000; Vector Laboratories, Burlingame, CA; $2.5 \mu \mathrm{g} / 50,000$ cells, goat anti-mouse IgG-PE (phycoerythrin), No. 115-115-164; Jackson ImmunoResearch, Baltimore, MD] at $4^{\circ} \mathrm{C}$ for $30 \mathrm{~min}$. Finally, cells were washed and resuspended in PBS and analyzed by flow cytometry (FCM). In the experiments using the anti-rat actin antibody, cells were permeabilized using the Fix \& Perm Kit (An-der-Grub Bio Research, Kaumberg, Austria) according to the manufacturer's instructions.

Acquisition rate was at least 60 events per second in low acquisition mode and at least 5000 events were measured. Acquisition and analysis were performed using Cell Quest 3.1. (Becton Dickinson) and the noncommercial FCM analyzing software WinMDI 2.8 for Windows (source: http:// facs.scripps.edu/software.html). Cells were analyzed in histograms displaying fluorescence 1 (fluoresceinisothiocyanate-labeled cells) and 2 (phycoerythrinlabeled cells) (9).

Immunohistochemistry. VSMCs, fibroblasts, and ECs were disseminated in a concentration of 200,000 cells $/ \mu \mathrm{L}$ on glass slides with removable plastic wells and fixated for $10 \mathrm{~min}$ with $4 \%$ paraformaldehyde. Permeabilization and nonspecific binding block were performed by incubating the slides for $1 \mathrm{~h}$ in blocking solution containing PBS $\left(\mathrm{pH} 7.4,20^{\circ} \mathrm{C}\right), 0.1 \%$ triton-X-100, $1 \%$ $\mathrm{BSA}$, and $2 \%$ goat serum.

Incubation of the cells was performed overnight at $4{ }^{\circ} \mathrm{C}$ with the following antibodies: for ECs rabbit anti-vWF (No. ab 6994; Abcam) 1:250 in PBS (pH $7.4,4^{\circ} \mathrm{C}$ ), for VSMCs monoclonal mouse anti-rat $\beta$-actin, smooth muscle Ab-1 (No. 06520; Dianova) 1:200 in PBS (pH 7.4, $4^{\circ} \mathrm{C}$ ), and for fibroblasts monoclonal biotinylated mouse anti-rat CD 90 (No. 554893; BD Biosciences) 1:50 in PBS $\left(\mathrm{pH} 7.4,4^{\circ} \mathrm{C}\right)$. Negative controls followed the same staining procedure in the absence of primary antibodies.

After washing three times with PBS, both secondary fluorescent goat anti-mouse antibodies (Alexa Fluor 488; MoBiTec GmbH, Goettingen, Germany) were applied each at a dilution of 1:1000 in PBS and incubated at room temperature for $1 \mathrm{~h}$. After being washed three times with PBS, slides were counterstained and mounted with aqueous 4,6-diamidino-2-phenylindole (DAPI) containing mounting media (Vectashield; Vector Laboratories). Microscopic analysis was performed under an epifluorescence microscope (AxioPlan 2 e; Imaging System, Carl Zeiss). Photographs were taken with a connected digital camera (AxioCAM MRc; Carl Zeiss) using AxioVision 4.2 software (Carl Zeiss).

MTT assay. The 3-(4,5-dimethylthiazol-2-yl)-2,5-diphenyltetrazolium bromide (MTT) assay was used to determine cell viability and proliferation in media with different FCS concentrations. An optimal FCS concentration is pivotal for the balance between cell culture viability and hyperproliferation. Uncoated 96-well plates were seeded with different cell densities to obtain nonconfluent $(25,000$ cells/well), subconfluent $(50,000$ cells/well), or confluent $(100,000$ cells/well $)$ cell cultures and cultivated overnight $\left(37^{\circ} \mathrm{C}, 21 \% \mathrm{O}_{2}\right.$, $\left.5 \% \mathrm{CO}_{2}\right)$. After $24 \mathrm{~h}$ with $1,5,10$, or $20 \% \mathrm{FCS}$, each well was incubated with $10 \mu \mathrm{L}$ of MTT reagent for $2 \mathrm{~h}$. Subsequently, $100 \mu \mathrm{L}$ of isopropanol in 0.04 NHCL was added, and after $2 \mathrm{~h}\left(20^{\circ} \mathrm{C}\right.$, lightproof) absorbance was quantified at a $570 \mathrm{~nm}$ by a microplate spectrophotometer. Reference measurements at $630 \mathrm{~nm}$ were done. The mitotic inhibitor staurosporine $(1 \mu \mathrm{M})$ was used as positive control.

ATP levels. Intracellular ATP levels were determined as previously described in VSMCs under normoxic $\left(21 \% \mathrm{O}_{2}, 5 \% \mathrm{CO}_{2}\right)$ and hypoxic conditions $\left(5 \% \mathrm{O}_{2}, 5 \% \mathrm{CO}_{2}\right)(10)$.

VEGF mRNA quantification. RNA was extracted using the isopropanol precipitation method and reversely transcribed using a commercial qPCR Core Kit (Eurogentec, Cologne, Germany). For real-time PCR, the following primer pairs and probes (BioTEZ, Berlin, Germany) were used: VEGF forward primer GTACCTCCACCATGCCAAGT, backward primer AGATGTCCACCAGGGTCTCA, probe 6-FAM-GCCCATGAAGTGGTGAAGTT-TAMRA, actin forward primer CCCTAAGGCCAACCGTGAAAAGATG, backward primer GAACCGCTCATTGCCGATGTGATG, probe 6-FAM-GTCGTACCACTGGCATTGTG-TAMRA. RNA expression differences were calculated using the delta $C_{\mathrm{T}}$ method with actin serving as endogenous control (11).

Free cytoplasmatic calcium. Intracellular calcium concentrations were assessed by the FURA-2-method in a microplate fluorometer at 362 and 335 nm (Infinite M200; Tecan Group Ltd., Männedorf, Switzerland) (12). Cell cultures were cultivated in 96-well plates at 50,000 cells/well for $24 \mathrm{~h}$ and then exposed to 21 versus $5 \%$ oxygen for $0.5 \mathrm{~h}$. Then FURA-2 (Sigma Chemical Co.-Aldrich) staining was performed following the manufacturer's instructions.

\section{RESULTS}

Using a complex immunomagnetic cell sorting technique, we established an improved and reproducible method for isolating ECs, VSMCs, and fibroblasts of high purity and viability from fetal rat DA. After preparation and enzymatic digestion of the different microvascular tissues, confluent primary mixed cell cultures were separated by MACS technique (Fig. 1). As indicated in Figure 2, the cell cultures were examined by phase-contrast microscopy before and after the separation. Each cell type showed typical morphological findings: in the case of ECs a "cobblestone" contact-inhibited monolayer was observed, whereas VSMCs showed the typical "hills and valleys" appearance. Fibroblasts were identified by their flat, elongated spindle-shaped process possessing morphology.

In addition, the purity of the different cell populations was determined by FCM (Fig. 3); a representative dot plot for the 


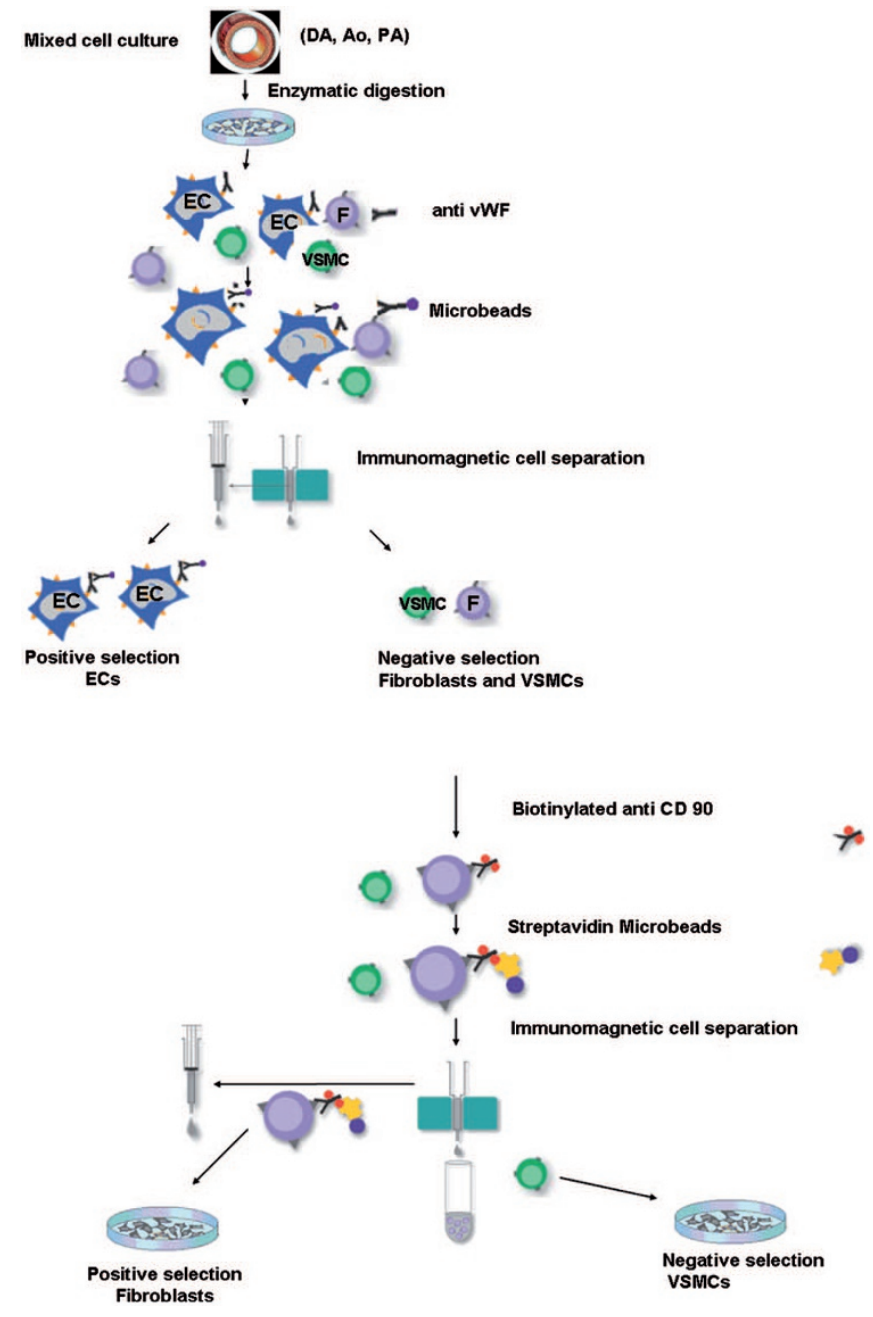

Figure 1. Synopsis of the immunomagnetic cell-separation process. F; fibroblasts. Modified according to Miltenyi Biotec.

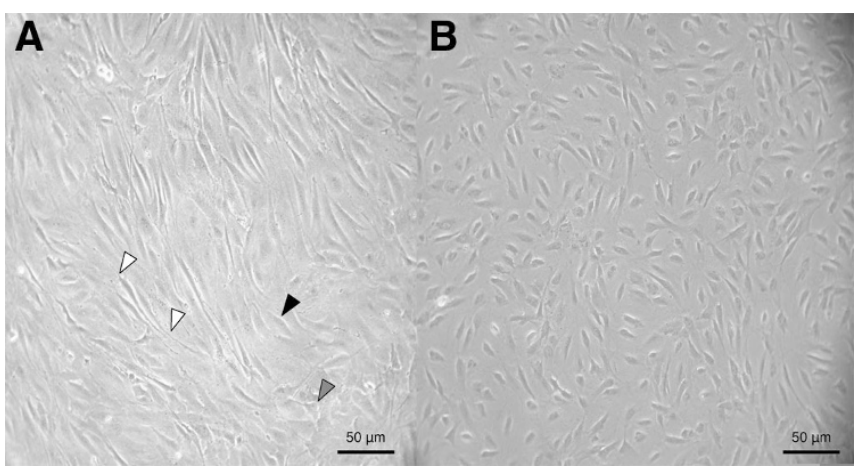

Figure 2. Phase-contrast appearance of cells from fetal rat DA before and after MACS separation; 200-fold magnification. A, Mixed cell culture. B, Nearly confluent ECs. Note the "cobblestone" contact-inhibited monolayer. White arrowhead, fibroblast; gray arrowhead, VSMC; and black arrowhead, EC.

EC analysis is given in Figure $3 B$. We obtained purities between 85 and 94\% for the different cell types (Table 1). Of note, Table 1 also shows the purity values from the aorta and PA for comparative reasons to demonstrate that our cell-typespecific isolation method is also applicable to other vessels.

In a next step, immunofluorescence staining was performed to visualize the different morphological features and the corresponding binding sites of the cell-specific antibodies
(Fig. 4), which also enabled us to exclude contamination by the different cell types during isolation. VSMCs, fibroblasts, and ECs show clear staining for their specific markers $\beta$-actin, CD90, and vWF, respectively. The minimal vWF staining in fibroblasts likely represents an artifact. However, expression of vWF in fibroblasts has been reported if cocultured with ECs or medium has been preconditioned (13). Furthermore, the morphological differences between the cell types as described above are visible.

Cell viability and proliferation were determined by MTT assay from cultures of different densities in media supplemented with different FCS concentrations. Cell viability depended on FCS dose and cell density. Only in the confluent cultures, cell viability was not influenced by changes in FCS concentrations, whereas viability decreased by 19 and $49 \%$ in the subconfluent culture with 5 and $1 \%$ FCS, respectively, compared with cultures with $20 \%$ FCS. In nonconfluent cultures, cell viabilities were decreased by 35 and $66 \%$ when supplemented with 5\% and $1 \%$ instead of $20 \%$ FCS, respectively. The positive control staurosporine reduced viability by $44 \%$ in the confluent culture with $20 \%$ FCS to $100 \%$ in the subconfluent culture with $1 \%$ FCS and in the nonconfluent culture with 5\% FCS. Because the confluent culture was robust to a 5\% FCS concentration, we recommend this FCS concentration to be used in future studies with this cell culture system.

To characterize the response of the isolated VSMCs to physiologic stimuli such as hypoxia, we measured the cytosolic calcium and ATP levels as well as VEGF mRNA expression under hypoxic and normoxic conditions. These experiments show that isolated VSMCs respond to 30-min hypoxia with a slight but significant decrease in intracellular calcium concentrations (82\% of normoxia; $p=0.012$ ) and decreased ATP levels (49\% of normoxia; $p=0.025$ ), whereas VEGF mRNA expression increased 3.2-fold.

\section{DISCUSSION}

Animal model. With our protocol, an improved and reproducible method for isolating ECs, VSMCs, and fibroblasts from rat DA was developed that yields high cell purity and viability despite the small size of the fetal rat vessels. To our knowledge, no comparable animal cell culture model of the fetal DA has so far been available. Furthermore, there is no human in vitro model to isolate and culture primary DA cells. Human DA tissue is only available from abortions or surgical specimens. Material from abortions is usually treated with formaldehyde and hence not suitable for molecular methods involving viable tissue. Therefore, examination of this material is limited to immunohistochemical or in situ hybridization protocols. Vital DA specimens from newborns without congenital heart disease (14) are rarely available $(15,16)$, because most patent DA are closed by surgical suture ligation or clip application in the NICU without excision of tissue to minimize potential complications. Second, the few tissue specimens available from surgical procedures are heterogeneous according to age, pathology, and therapy and hence not suitable for 
A
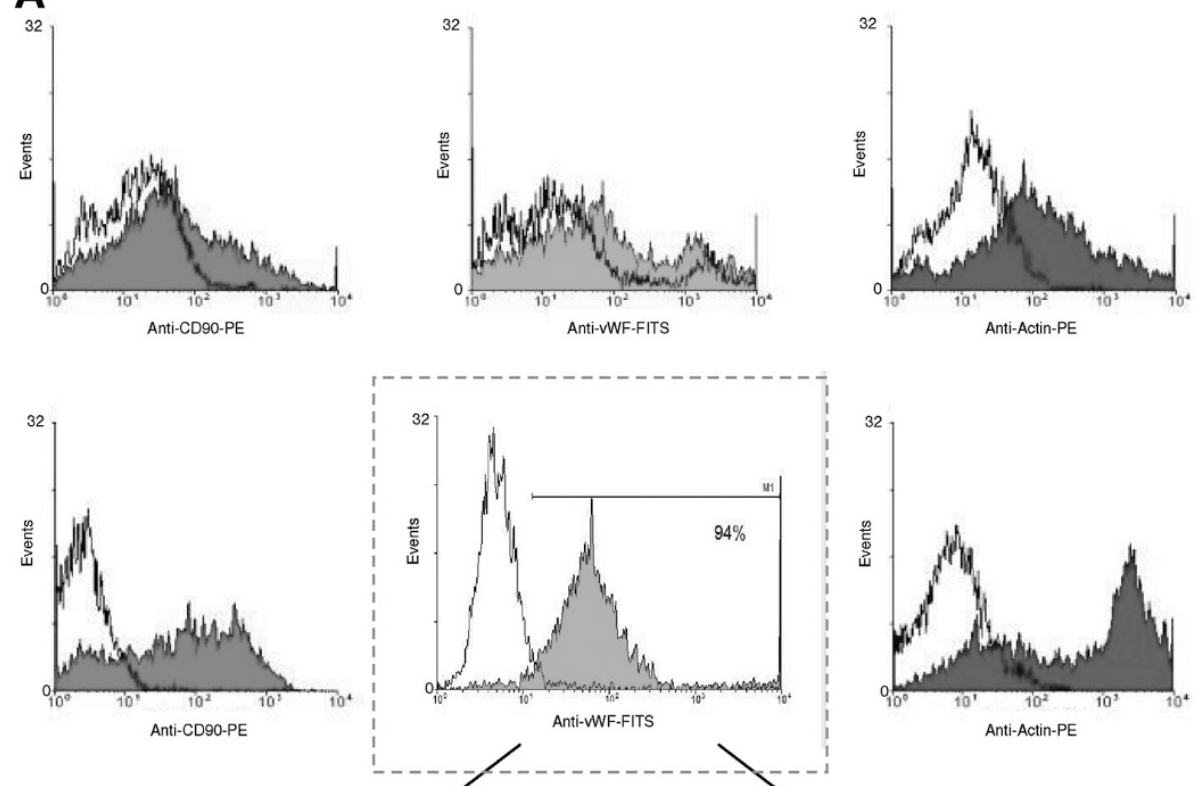

Figure 3. FCM analysis of DA cells. A, Overview of FCM histograms before (upper row) and after (lower row) immunomagnetic cell separation for fibroblasts (anti-CD 90, first column), ECs (anti-vWF, second column), and VSMCs (antiactin, third column). Note that in the lower row the entire peak has shifted to the right, indicating that a high percentage $(94 \%$ of the ECs) of the isolated cells is recognized by their specific antibodies. In each graph, the abscissa is a $\log$ scale of fluorescence and the ordinate represents the cell count. $B$, Representative dot plots of anti-vWF MAb FITC-labeled ECs to demonstrate the purity after the immunomagnetic cell separation $(+)$. Corresponding negative isotype control (-). Results shown as scatter-gated fluorescence analysis [side scatter (ssc) vs fluorescence 1].

B
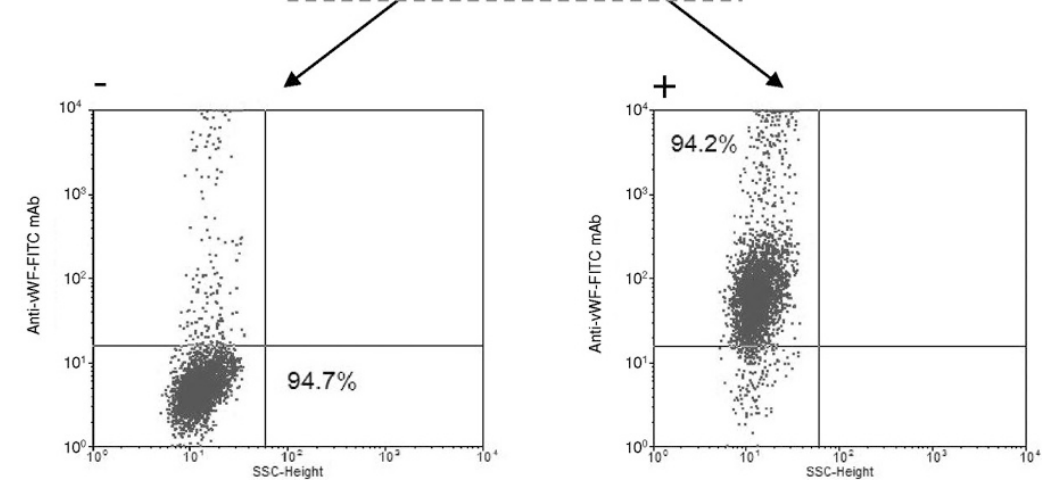

Table 1. Purity of the different cell types

\begin{tabular}{|c|c|c|c|c|c|c|c|c|c|}
\hline \multirow[b]{2}{*}{ Mean \pm SD (\%) } & \multicolumn{3}{|c|}{$\begin{array}{c}\text { Endothelium }(n=17) \\
92.73 \pm 4.17\end{array}$} & \multicolumn{3}{|c|}{$\begin{array}{l}\text { Muscle }(n=17) \\
85.41 \pm 4.96\end{array}$} & \multicolumn{3}{|c|}{$\begin{array}{c}\text { Fibroblast }(n=18) \\
\quad 93.77 \pm 3.77\end{array}$} \\
\hline & DA $(n=6)$ & $\mathrm{PA}(n=5)$ & Aorta $(n=6)$ & $\mathrm{DA}(n=5)$ & $\mathrm{PA}(n=6)$ & Aorta $(n=6)$ & $\mathrm{DA}(n=6)$ & PA $(n=6)$ & Aorta $(n=6)$ \\
\hline Mean \pm SD $(\%)$ & $93.10 \pm 2.03$ & $92.06 \pm 5.38$ & $92.93 \pm 5.27$ & $87.65 \pm 6.53$ & $82.59 \pm 2.82$ & $86.34 \pm 4.61$ & $94.58 \pm 4.03$ & $93.03 \pm 5.15$ & $93.69 \pm 2.04$ \\
\hline
\end{tabular}

The upper row shows the total purity of the different cell types after immunomagnetic cell separation. The lower row shows the purity of the cells subdivided

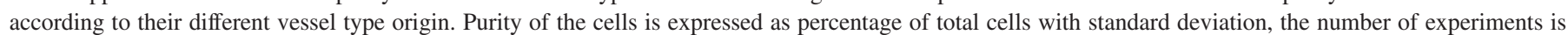
given in paragraphs.

systematic functional investigations, especially because oxygen and prostaglandin treatment is frequently applied.

Therefore, animal models provide a reasonable alternative approach. In DA research, in vivo models and organotypic models are used, mostly to perform functional tests. However, these models are also hampered by the fact that function and gene expression of individual cell types can only be detected by immunohistochemical or in situ hybridization methods.

Species used in DA research include sheep, pig, baboon, rabbit, guinea pig, hamster, rat, and mouse. Large animal models although being close to human physiology have the disadvantage of intricate handling, long gestation periods, and a small number of offspring. In small animal models, the DA has been thoroughly investigated and characterized on several levels. Furthermore, a large variety of validated molecular tools such as antibodies, probes, and primers are commercially available for rat and mouse. Although the murine model is usually considered to be more human homologous, its potential use was not suitable because of the small size of the fetal situs. Taking all these facts into account, we decided to establish our method in the rat model.

Cell culture. The primary isolation yielded only a small number of cells. To increase the rate of yield, we had to use cell cultures that had to be passaged up to three times instead of a primary cell culture. We are aware of the fact that the used enzyme-based disaggregation of the tissue might be damaging and potentially alters the functional properties of the isolated cells. However, this issue is unavoidable in ex vivo cell cultures and well-established culture systems, such as human umbilical vein ECs that are widely used for functional studies, inherit the same limitations $(17,18)$.

Cell line cross contamination (mostly fibroblasts) was widely avoided by using individual culture media for each cell type and FCM authentication at an early passage. Cells were 


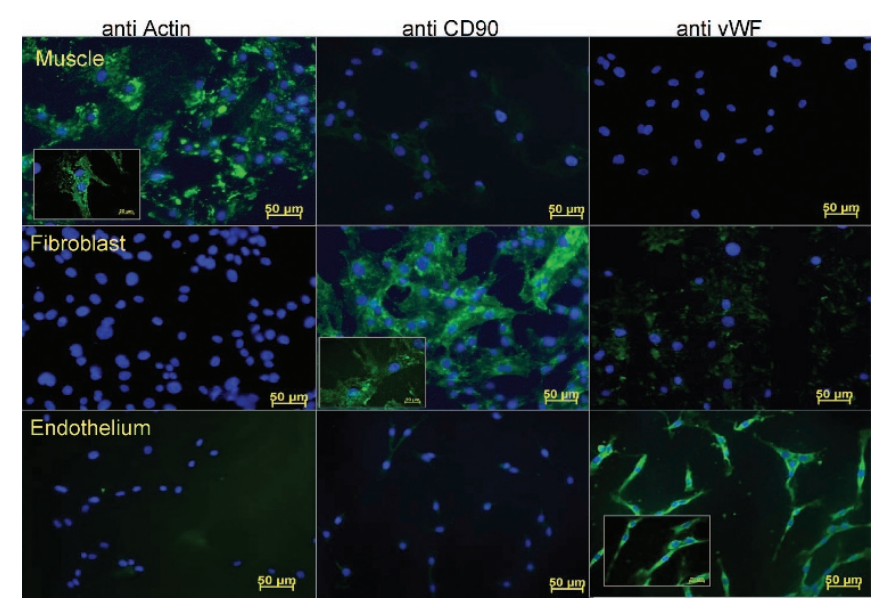

Figure 4. Immunfluorescence staining. Specimens are 4,6-diamidino-2phenylindole (DAPI) counterstained (blue). First column, labeling of VSMCs, fibroblasts, and ECs with antiactin antibody resulting in a positive staining of the VSMCs with their "hills and valleys" appearance. Second column, immunofluorescence for anti-CD90 is apparent in fibroblasts. Third column, ECs are positive for anti-vWF while VSMCs do not stain. The minimal vWF staining in fibroblasts likely represents an artifact.

grown and maintained at normoxia $\left(37^{\circ} \mathrm{C}, 5 \% \mathrm{CO}_{2}\right)$, which differs significantly from the oxygen tension of fetal arterial blood. Therefore, an alteration of oxygen-dependent signaling pathways cannot be ruled out in our cell culture model. We measured the effect of hypoxia on cytosolic calcium levels in VSMCs. These experiments show that isolated VSMCs respond to hypoxia with a slight but significant decrease in intracellular calcium concentrations. These findings are in line with the current literature which shows that with an increasing number of passages VSMCs gradually loose their potential to respond to hypoxia under culture conditions (19). Our cell cultures underwent up to three passages and were cultured for up to $15 \mathrm{~d}$, and therefore still show a minimal calcium response. In addition, we assessed ATP contents in cells cultured under normoxic and hypoxic conditions and show that ATP content is reduced under hypoxia representing a metabolic response to the hypoxic stimuli. Because our cell culture model should especially be applicable to gene expression studies, we furthermore investigated the effect of hypoxia on the expression of the hypoxia-responsible gene VEGF. VEGF mRNA levels were increased by hypoxia in ductal VSMCs indicating a functional transcriptional response to hypoxia.

Immunomagnetic cell sorting. The purity of the different cell types was significantly improved compared with other recently described methods (20). In contrast to former protocols, we used a complex immunomagnetic separation technique to improve the purity of the different cell populations of interest. In a first step, ECs and then fibroblasts were obtained by positive selection, a direct and specific way to isolate the target cells from a heterogeneous cell suspension by indirect magnetic labeling using cell-specific antibodies. Although this approach achieves a high grade of purity in the specific cell population (21), several studies have reported that intracellular signaling could be activated downstream from the antibody binding site. The function of positively selected cells could therefore be altered by the procedure used to purify them $(22,23)$. We used anti-vWF antibody for the isolation of ECs and anti-CD 90 for fibroblast isolation. CD 90 is a 25- to 37-kD heavily $N$-glycosylated, glycophosphatidylinositolanchored conserved cell surface protein with a single V-like immunoglobulin domain, originally discovered as a thymocyte antigen and expressed on mesenchymal stem cells and fibroblasts. vWF is a blood glycoprotein involved in hemostasis and a useful marker for ECs. We do not believe that binding of either antibody causes significant functional or morphological changes but the possibility exists and needs further investigation.

In contrast to ECs and fibroblasts, VSMCs were isolated using negative selection, a method involving the removal of the other cell types (ECs and fibroblasts) from the cell culture. This method has the advantage of isolating "untouched" cells, because the cells of interest have not been attached to the antibodies on the magnetic beads. This avoids any possible antibody-induced intracellular signaling.

However, negative selection protocols are technically more challenging and if unwanted cells are ineffectively depleted, some might, however, be enriched in the negatively selected fraction. In our model, the purity of the VSMC cultures was lower $(85 \%)$ compared with other protocols (24). This might be attributable to the fact that in the experimental setting of Yokoyama et al., the cells were used after passages 4 to 6 , although in our model nearly confluent conditions were already found after passages 2 to 3 . Recently published data have shown several disparities between freshly isolated vessels and cultured VSMCs, which generally limits the use of cultured vessels for studying excitation-contraction (25).

FCM analysis. Although in earlier studies the purity of the different cell lines was determined morphologically by phasecontrast microscopy and/or by immunofluorescence, we analyzed the purity of the different cell types using FCM and were able to demonstrate a purity of up to $95 \%$ (Fig. 3B). In addition, immunofluorescent staining was performed to elucidate the different morphological findings of the different cell subtypes. Fluorescence-activated cell sorting as a specialized type of FCM in our experimental setting was not possible because of the limited quantity of material that could be supplied for this method and the relatively low recovery rate (26).

Aims. We developed an improved and reproducible method for isolating ECs, VSMCs, and fibroblasts of high yield and purity from rat DA. In contrast to in vivo animal models where the vessel could only be investigated as one complex structure, this method allows for separate investigations of the different cell types and their functions during the developmental steps of DA closure. In conclusion, this new method helps investigate the different vessel-specific cell types before, during, and after birth. The purified different cell subtypes can be used for protein and gene expression profiling as well as for functional studies and therefore represent an important tool to improve our understanding of DA closure.

Acknowledgments. We thank Evelyn Strauß and Sonja Wollersheim for their assistance. 


\section{REFERENCES}

1. Rudolph AM, Heyman MA 1974 Fetal and neonatal circulation and respiration. Annu Rev Physiol 36:187-207

2. Weber SC, Rheinlaender C, Sarioglu N, Peiser C, Rudiger M, Obladen M, Koehne PS 2008 The expression of VEGF and its receptors in the human ductus arteriosus. Pediatr Res 64:340-345

3. Rheinlaender C, Weber SC, Sarioglu N, Strauss E, Obladen M, Koehne P 2006 Changing expression of cyclooxygenases and prostaglandin receptor EP4 during development of the human ductus arteriosus. Pediatr Res 60:270-275

4. Clyman RI, Waleh N, Black SM, Riemer RK, Mauray F, Chen YQ 1998 Regulation of ductus arteriosus patency by nitric oxide in fetal lambs: the role of gestation, oxygen tension, and vasa vasorum. Pediatr Res 43:633-644

5. Yokoyama U, Minamisawa S, Quan H, Akaike T, Suzuki S, Jin M, Jiao Q, Watanabe M, Otsu K, Iwasaki S, Nishimaki S, Sato M, Ishikawa Y 2008 Prostaglandin E2-activated Epac promotes neointimal formation of the rat ductus arteriosus by a process distinct from that of cAMP-dependent protein kinase A. J Biol Chem 283:28702-28709

6. Yokoyama U, Minamisawa S, Ishikawa Y 2010 Regulation of vascular tone and remodeling of the ductus arteriosus. J Smooth Muscle Res 46:77-87

7. Costa M, Barogi S, Socci ND, Angeloni D, Maffei M, Baragatti B, Chiellini C, Grasso E, Coceani F 2006 Gene expression in ductus arteriosus and aorta: comparison of birth and oxygen effects. Physiol Genomics 25:250-262

8. Johnson JA, Barman SA 2004 Protein kinase C modulation of cyclic GMP in rat neonatal pulmonary vascular smooth muscle. Lung 182:79-89

9. Dittrich S, Lippek F, Gratopp A, Grosse-Siestrup C, Lange PE, Buhrer C 2002 Intravascular granulocyte aggregates caused by the selectin-binding carbohydrate fucoidin in pig kidneys. Clin Exp Pharmacol Physiol 29:909-914

10. Diestel A, Troeller S, Billecke N, Sauer IM, Berger F, Schmitt KR 2010 Mechanisms of hypothermia-induced cell protection mediated by microglial cells in vitro. Eur J Neurosci 31:779-787

11. Livak KJ, Schmittgen TD 2001 Analysis of relative gene expression data using real-time quantitative PCR and the 2(-Delta Delta C(T)) method. Methods 25:402408

12. Grynkiewicz G, Poenie M, Tsien RY 1985 A new generation of $\mathrm{Ca}^{2+}$ indicators with greatly improved fluorescence properties. J Biol Chem 260:3440-3450

13. Giddings JC, Hogg S, Legg IR, Hughes IA 1986 The relationship between von Willebrand factor antigen and fibronectin in human plasma, endothelial cells and fibroblasts in culture. Thromb Res 44:291-301
14. Michelakis ED, Rebeyka I, Wu X, Nsair A, Thebaud B, Hashimoto K, Dyck JR, Haromy A, Harry G, Barr A, Archer SL $2002 \mathrm{O}_{2}$ sensing in the human ductus arteriosus: regulation of voltage-gated $\mathrm{K}+$ channels in smooth muscle cells by a mitochondrial redox sensor. Circ Res 91:478-486

15. Mandhan PL, Samarakkody U, Brown S, Kukkady A, Maoate K, Blakelock R, Beasley S 2006 Comparison of suture ligation and clip application for the treatment of patent ductus arteriosus in preterm neonates. J Thorac Cardiovasc Surg 132:672674

16. Salomon NW, Anderson RM, Copeland JG, Allen HD, Goldberg SJ, Sahn DJ 1979 A rational approach to ligation of patent ductus arteriosus in the neonate. Chest 75:671-674

17. Willam C, Koehne P, Jurgensen JS, Grafe M, Wagner KD, Bachmann S, Frei U, Eckardt KU 2000 Tie2 receptor expression is stimulated by hypoxia and proinflammatory cytokines in human endothelial cells. Circ Res 87:370-377

18. Graf K, Koehne P, Grafe M, Zhang M, Auch-Schwelk W, Fleck E 1995 Regulation and differential expression of neutral endopeptidase 24.11 in human endothelia cells. Hypertension 26:230-235

19. Weir EK, Archer SL 2010 The role of redox changes in oxygen sensing. Respir Physiol Neurobiol 174:182-191

20. Rabinovitch M, Beharry S, Bothwell T, Jackowski G 1988 Qualitative and quantitative differences in protein synthesis comparing fetal lamb ductus arteriosus endothelium and smooth muscle with cells from adjacent vascular sites. Dev Biol $130: 250-258$

21. Horgan K, Shaw S, Boirivant M 2009 Immunomagnetic purification of $\mathrm{T}$ cell subpopulations. Curr Protoc Immunol Chapter 7:Unit 7.4

22. Campbell SB, Komata T, Kelso A 2001 CD4 ligation promotes the IL-4-independent development of IL-4-producing clones from naive CD4(+) T cells. J Immunol 167:5610-5619

23. Bernard F, Jaleco S, Dardalhon V, Steinberg M, Yssel H, Noraz N, Taylor N, Kinet S 2002 Ex vivo isolation protocols differentially affect the phenotype of human CD4+ T cells. J Immunol Methods 271:99-106

24. Yokoyama U, Minamisawa S, Adachi-Akahane S, Akaike T, Naguro I, Funakoshi K, Iwamoto M, Nakagome M, Uemura N, Hori H, Yokota S, Ishikawa Y 2006 Multiple transcripts of $\mathrm{Ca} 2+$ channel alpha1-subunits and a novel spliced variant of the alpha1C-subunit in rat ductus arteriosus. Am J Physiol Heart Circ Physiol 290:H1660-H1670

25. Manoury B, Etheridge SL, Reid J, Gurney AM 2009 Organ culture mimics the effects of hypoxia on membrane potential, $\mathrm{K}(+)$ channels and vessel tone in pulmonary artery. Br J Pharmacol 158:848-861

26. Orfao A, Ruiz-Arguelles A 1996 General concepts about cell sorting techniques Clin Biochem 29:5-9 